\title{
Exploring the reasons for the sensitivity to change of a patient preference measure, compared with the KOOS questionnaire in patellofemoral osteoarthritis
}

\author{
Matthew Parkes ${ }^{1,2^{*}}$, Michael Callaghan ${ }^{1,2}$, David Felson ${ }^{1,3}$ \\ From 3rd International Clinical Trials Methodology Conference \\ Glasgow, UK. 16-17 November 2015
}

\section{Background}

We have previously found that one patient preference measure has increased sensitivity to change (Parkes et al. 2014, Arthritis Rheum 66 (11): S562). We explored the reasons why this particular measure has increased sensitivity, using data from the BRACE trial (ISRCTN50380458).

\section{Methods}

The 'pain on nominated aggravating activity' visual analogue scale $\left(\mathrm{VAS}_{\mathrm{NA}}\right)$, was compared to the Knee Osteoarthritis Outcome Score (KOOS) questionnaire. The distribution of painful activities selected by patients using the $\mathrm{VAS}_{\mathrm{NA}}$ in the BRACE trial was compared to activities covered by the KOOS. We also compared the standardised between-groups change in pain in the $\mathrm{VAS}_{\mathrm{NA}}$ and the KOOS to see whether the magnitude in change was comparable.

\section{Results}

Two-thirds of patients nominated pain using stairs, an activity captured by the KOOS. A further 28 subjects (22.2\%) nominated squatting, bending or kneeling, and others nominated running (3.2\%), activities not captured by KOOS. Standardised changes were generally higher for the $\mathrm{VAS}_{\mathrm{NA}}$ than for the KOOS total score (for example, stairs subgroup change -0.26 vs. -0.11 ), especially for patients choosing activities not covered by the KOOS (squatting, bending and kneeling subgroup change -0.26 vs. -0.16). In this subgroup, many of the individual KOOS items change little following treatment.

University of Manchester, Manchester, UK

Full list of author information is available at the end of the article

\section{Conclusion}

The VAS $_{\text {NA }}$ was more sensitive to change than the KOOS both in subgroups whose painful activity overlapped with KOOS items and those that did not. Questions which have less relevance may add 'noise' to the signal for change in pain, which could explain the KOOS's decreased sensitivity to change.

\section{Authors' details}

'University of Manchester, Manchester, UK. ${ }^{2} \mathrm{NIHR}$ Manchester Musculoskeletal Biomedical Research Unit (BRU), Manchester, UK. ${ }^{3}$ Boston University, Boston, MA, USA.

Published: 16 November 2015

doi:10.1186/1745-6215-16-S2-P66

Cite this article as: Parkes et al:: Exploring the reasons for the sensitivity to change of a patient preference measure, compared with the KOOS questionnaire in patellofemoral osteoarthritis. Trials 2015 16(Suppl 2):P66.

Submit your next manuscript to BioMed Central and take full advantage of:

- Convenient online submission

- Thorough peer review

- No space constraints or color figure charges

- Immediate publication on acceptance

- Inclusion in PubMed, CAS, Scopus and Google Scholar

- Research which is freely available for redistribution 